\title{
Influence of social capital offline and online on early-stage entrepreneurs
}

\author{
Tatiane Andreza de Souza Silva and Victor Silva Corrêa \\ Administração, Universidade Paulista, São Paulo, Brazil \\ Gláucia Maria Vasconcellos Vale \\ Programa de Pós-Graduação em Administração - PPGA/PUC Minas, \\ Pontificia Universidade Catolica de Minas Gerais, Belo Horizonte, Brazil, and \\ Ernesto Michelangelo Giglio \\ Administração, Universidade Paulista, São Paulo, Brazil
}

\begin{abstract}
Purpose - The purpose of this article is to investigate if and how social capital offline - stemming from face-toface interactions - and social capital online - stemming from social digital media - can influence early-stage entrepreneurs, i.e. ventures with up to 42 months of existence.

Design/methodology/approach - The authors used herein a qualitative research approach. The method used was the case study. The authors investigated three early-stage entrepreneurs in order to achieve the objective of the paper. These entrepreneurs are both the unit of analysis and the unit of observation.

Findings - The outcomes of this research indicate (1) the combined importance of social capital offline and online; (2) the different performance of the two different types of social capital (they seem to operate in relatively distinct ways) and (3) the existence of recursiveness between resources stemming from the two social spheres (offline and online).

Research limitations/implications - As research limitations, the authors point out the following: (1) the use of semistructured interviews as the only data collection instrument; (2) the limitation of the outcomes to entrepreneurs only (3) the absence of information on the performance of the business ventures; the focus of the paper was only on establishing causality between social capital offline and online and entrepreneurial performance. Originality/value - This paper provides important research contributions. Initially, the paper presents a range of offline and online variables, which can be used in further research. At the same time, the paper emphasizes the combined impact of social capital offline and online, expanding the literature related to entrepreneurship. Moreover, this study proposes the creation of an integrative model. Finally, the authors point out the need for new theoretical and empirical studies on the subject, which still presents a gap in the literature.
\end{abstract}

Keywords Social capital, Entrepreneurship, Social media, Online, Offline

Paper type Research paper

\section{Introduction}

As the access to the Internet is made more available, entrepreneurs and companies have been seeking socialmedia websitesas mechanisms to supportand expand business. Accordingly,Smith, Smith and Shaw (2017, p. 18) affirm that "entrepreneurs are increasingly using social media to interact with others". Confirming to such a statement, new investigations start gaining more space and becoming more important (Cho \& Sagynov, 2015; Hanna, Rohm \& Crittenden, 2011;

(C) Tatiane Andreza de Souza Silva, Victor Silva Corrêa, Gláucia Maria Vasconcellos Vale and Ernesto Michelangelo Giglio. Published in Revista de Gestão. Published by Emerald Publishing Limited. This article is published under the Creative Commons Attribution (CC BY 4.0) license. Anyone may reproduce, distribute, translate and create derivative works of this article (for both commercial and noncommercial purposes), subject to full attribution to the original publication and authors. The full terms of this license may be seen at: http://creativecommons.org/licences/by/4.0/legalcode

This research was supported by the National Council for Scientific and Technological Development CNPq - Brazil (process number 433381/2018-3). 
REGE 27,4

Nasir, Nawi, Mamun, Fazal \& Raston, 2017). Considering studies on entrepreneurship, themes traditionally considered important have been rescued and brought to this new digital world, where online relations prevail. This is the case of networks and social capital.

The social capital, which is represented by characteristics of networks (HernándezCarrión, Camarero-Izquierdo \& Gutiérrez-Cillán, 2017) and by the set of resources that individuals "may access through their personal networks" (Stam, Arzlanian \& Elfring, 2014, p. 153), enables entrepreneurs to identify new opportunities (Stam, Arzlanian \& Elfring, 2014), gain credibility, access information, gain access to scarce financial and intellectual resources (Vixathep, 2017), expand commercial and business capabilities (HernándezCarrión, Camarero-Izquierdo \& Gutiérrez-Cillán, 2017) among others. It is a key asset for entrepreneurs and entrepreneurship (Afandi, Kermani, \& Mammadov, 2017; Bastié, Cussy \& Le Nadant, 2016; Bucholtz, 2019; Pedrini, Bramanti \& Cannatelli, 2016; Vixathep, 2017).

With the proliferation of technological platforms and social media websites, e.g. Facebook, Twitter and WhatsApp, it is possible to notice some modifications in the type of personal and business relations; most of them switched from face-to-face interactions into digital environment relations (Smith, Smith \& Shaw, 2017). Moreover, the pandemic provoked by the new coronavirus (COVID-19) and the consequent importance of isolation and social distancing are, for instance, encouraging and forcing companies to search for communication alternatives and maintenance of business in the digital environment (Nassif, Corrêa \& Rosseto, 2020). Such changes exact from social capital researchers create new reflections and observations on the characteristics of such interactions, in addition to the influence of social capital for entrepreneurs and their ventures.

Accordingly, Smith, Smith and Shaw (2017, p. 21) affirm that "differences in the on and offline contexts could impact the types of opportunities entrepreneurs" have access to "and the extent to which their social capital is developed, accessed, and used" (Smith, Smith \& Shaw, 2017, p. 21). Confirming to the authors "people build, maintain, and use social networks" in a way that is "substantively different than with face-to-face interactions" (Smith, Smith \& Shaw, 2017,p. 22). At the same some, some evidences - still poorly explored in the literature-suggest "potential differences in entrepreneurs' online and offline networking behavior" (Smith, Smith \& Shaw, 2017, p. 18) when it comes to accumulating social capital.

Our paper is inserted in the essence of such considerations. From a theoretical perspective, our purpose is to investigate the influence of entrepreneurs' social capital online and offline. In this investigation, social capital offline will be understood as the set of resources that entrepreneurs can access through what Williams (2006, p. 593) called "real life"; in other words, personal relations and face-to-face interactions (Smith, Smith \& Shaw, 2017; Stam, Arzlanian \& Elfring, 2014). Social capital online will be understood herein as the resources obtained from entrepreneurs through interactions on online social media (Bucholtz, 2019; Mahmood, Zakar \& Zakar, 2018; Naseri, 2017; Wahid \& Indarti, 2013).

From an empirical perspective, our paper aims to insert the social capital theme into the reality of early-stage entrepreneurs, whose business is in existence up to 42 months (GEM, 2018). It is very important to provide better understand of such empirical context (Bernardino \& Freitas Santos, 2019; GEM, 2018). Approximately 25 million entrepreneurs (about $46 \%$ of the total number of entrepreneurs in the country) are considered in "early-stage entrepreneurial activity" according to parameters adopted by the Global Entrepreneurship Monitor (GEM, 2018). In 2018, more than 2.5 million companies were created, which represents an increase of $15 \%$ when compared to the previous year (https://www. serasaexperian.com.br/).

Also, literature has tried to figure out how and why such ventures tend to be more prone to failure and mortality. As observed by Fosić, Kristić and Trusić (2017, p. 339), "the first stage of starting a business is the most challenging stage of an entrepreneurial career". Recent data provided by Sebrae [1] indicate that one in every four companies fails within the first two 
years of operation (www.sebrae.com.br). It is, therefore, important to understand the distinct factors inherent in companies, especially the relational ones (related to offline and online social capital), which may influence the trajectory of entrepreneurs in the early stage of their entrepreneurial careers.

It seems that such debate has not reached Brazil yet. A search performed by us in some of the main databases (Spell and Capes Journals) and national events (EnANPAD, Egepe and Semead) did not identify the existence of articles that investigated if and how social capital offline and online can influence early-stage entrepreneurs. The search encompassed published papers over the past five years with combination of a few interest terms in the title or keywords (social media websites*, social capital or early*; social capital and creation of a company* and social media and entrepreneur*). Different questions guided the investigation conducted herein; the most relevant ones were as follows: (1) Does social capital offline and online influence early-stage entrepreneurs? If they do, how is such influence exerted?

As pointed out previously, the literature on social capital was used, herein, in order to support the debate brought by us. We emphasize the existence of different approaches and levels of analysis on the theme (Han, 2018; Naseri, 2017; Ryu, 2017). Two of them, considered the "most important dimensions" of social capital (Ryu, 2017, p. 4), "have gained prominence in entrepreneurship literature" (Smith, Smith \& Shaw, 2017, p. 20): bonding social capital and bridging social capital (Birendra, Morais, Seekamp, Smith \& Peterson, 2018). The first approach attaches social capital to the immersed resources available in the dense/cohesive networks, which are constituted of intense and frequent interaction among individuals (Coleman, 1988; Granovetter, 1973). The second approach considers social capital as the gains achieved through linking distant networks, i.e. the resources achieved through less frequent contacts (Burt, 2009, 2015; Bucholtz, 2019).

Our paper focuses on both approaches (bonding and bridging) by incorporating them as integral parts of each dimension considered herein: offline and online. In other words, we consider that social capital offline and online are constituted of elements related both to the bonding and to the bridging approach. By doing so, important research gaps tend to overcome. Although the bonding and bridging dimensions have already been explored in the offline context, when considering the online environment (i.e. digital social media) its manifestations are not sufficiently clear (Bucholtz, 2019; Smith, Smith \& Shaw, 2017). Bucholtz (2019) emphasizes that only a few studies tried to investigate the juxtaposition between both social capitals (bonding and bridging) in the online communication. As reported by the author, "the evidence of ambiguity of the characteristics of bridging and bonding social capital in online environments are limited, but worthy of further inquiry" (Bucholtz, 2019, p. 4).

There is also a gap in literature associated with the benefits that can be obtained by entrepreneurs through social media. In fact, "few studies have considered how entrepreneurs build and employ social capital in the context of online networks" (Smith, Smith \& Shaw, 2017, p. 18). According to the authors, "little is known about how entrepreneurs establish social capital online" (Smith, Smith \& Shaw, 2017, p. 19). A third gap in the literature relates to the possible associations between social capital offline and online. Conforming to Smith, Smith and Shaw (2017, p. 18), "it is not clear, however, to what extent or how entrepreneurs' social capital manifests differently online than offline". Besides, it is not clear if the social capital of the offline environment, usually developed over longer periods of time, is somehow “transferable to entrepreneurs' online relationships” (Smith, Smith \& Shaw, 2017, p. 21).

By trying to fill these literature gaps, our article makes significant contributions. The first contribution is the presentation of a set of offline and online variables, which can be used in further field research. The second highlights the influence of the combined offline and online social capitals on early-stage entrepreneurs, which broadens the developing literature on social capital and entrepreneurship. The third contribution indicates how each type of social 
REGE 27,4 capital (offline and online) influences early-stage entrepreneurs, which could be used to boost entrepreneurial initiatives. The fourth proposes the creation of an integrative model between social capital offline and online. The fifth and last indicates the need to develop further theoretical and empirical studies, which remain unapproached.

\section{Theoretical framework}

Social capital can be considered "two of the most influential concepts in social science over the past two decades" (Lewis \& Chamlee-Wright, 2008, p. 107). Nevertheless, when the concept is associated with entrepreneurial studies, there is a lack of a consolidated theoretical core in the literature (Smith, Smith, \& Shaw, 2017; Williams, Huggins \& Thompson, 2017). In accordance with Smith, Smith and Shaw (2017), the concept lacks precision and consistency; it is, therefore, important "to delve further into the myriad of definitions that have been employed to identify and explain the phenomena that can be considered to constitute social capital" (Williams, Huggins \& Thompson, 2017, p. 2).

Part of such conceptual inaccuracy relates to the different dimensions and level of analysis associated with the concept (Fukugawa, 2018; Lang \& Fink, 2019). Kim and Kang (2014) emphasize that there are "various kinds of social capital" (Kim \& Kang, 2014, p. 48). As kinds of social capital, one can mention the localized social capital (Giudici, Guerini, \& RossiLamastra, 2018), internal and external social capital (Chen \& Zhou, 2017), instrumental social capital (Rooks, Klyver \& Sserwanga, 2016), organizational social capital (Luu, 2017) among others. Two of them, from a relational and structural perspective (Fukugawa, 2018), "have gained prominence in entrepreneurship literature" (Smith, Smith \& Shaw, 2017, p. 20).

The first is known as bonding social capital. It is to be understood as the benefits arising from the thickening of the social network, which results in the strengthening of ties among individuals of a social structure (Coleman, 1988, 1999). The second is called bridging social capital. It is to be interpreted as the benefits stemming from the ability of the entrepreneur to intermediate "empty spaces" in the network by bridging the gap among individuals far from one another (Birendra, Morais, Seekamp, Smith, \& Peterson, 2018; Hernández-Carrión, Camarero-Izquierdo \& Gutiérrez-Cillán, 2017; Naseri, 2017; Wahid \& Indarti, 2013). Bonding and bridging "are perhaps the most important dimensions" (Ryu, 2017, p. 4) of social capital and "have received the most attention" over the past years (Han, 2018).

In our article, social capital is to be understood as the characteristics of the network (Hernández-Carrión, Camarero-Izquierdo \& Gutiérrez-Cillán, 2017) and as "a resource located in an actor's internal ties (associated with bonding social capital) and external ties (associated with bridging and linking social capital)" (Hernández-Carrión, Camarero-Izquierdo \& Gutiérrez-Cillán, 2017, p. 63). In other words, we consider social capital as the "resources that can be accessed or mobilized through ties in the networks" (Bucholtz, 2019, p. 3), such as the benefits obtained by entrepreneurs "through their personal networks" (Stam, Arzlanian, \& Elfring, 2014, p. 153). On the one hand, bonding implies homogeneity among connections; on the other hand, bridging suggests the existence of heterogeneity among them (Mahmood, Zakar \& Zakar, 2018; Naseri, 2017).

The origin of studies on connecting social capital (bonding) can be found in the research by Granovetter (1973) on social ties and in propositions by Coleman $(1988,1990)$ on the benefits of occlusal networks. According to Coleman $(1988,1990)$, closed networks provide important advantages to people. We highlight herein three of them; the first is related to the obligations and trust present in social grouping. According to Coleman (1988, p. 103), "individuals in social structures with high level of obligations outstanding at any time have more social capital on which they can draw". The second advantage relates to the application of sanctions. This attribute reduces the risk of trusting each other and stimulates individuals to develop a mutually cooperative behavior (Coleman, 1988). At last, the third benefit is related 
with the facilitated access to resources (social capital) in closed groups. The author claims that "one means by which information can be acquired is by use of social relations that are maintained for other purposes" (Coleman, 1988, p. 104).

There is another approach on social capital (bridging social capital) that derived was from Granovetter's (1973) studies and deals with the importance and strength of weak ties, which complements the studies of Burt $(2009,2015)$ on weak connections or structural holes. The approach emphasizes the importance of overcoming connection holes and connecting to different - or structurally distant - people, i.e. immersed in distinct networks. Such distance or difference was denominated by Burt $(2009,2015)$ as the structural hole. According to the author, individuals capable of establishing weak links with people immersed in different groupings - dense and separated from one another - are in a more strategic position. According to Burt (1997, p. 342), "networks rich in structural holes present opportunities for entrepreneurial behavior". When connecting people that were until this moment unlinked, entrepreneurs gain access to important advantages, unreachable in other ways. One of them, which is also important for the development of our paper, is the possibility to obtain new information and resources. Table 1 summarizes the main information on bonding and bridging capital, indicating each correspondent author.

It is possible to observe, based on the discussion on social capital approached herein, that the bonding and bridging dimensions associated specifically with the offline context; i.e. "real-life" interactions (Williams, 2006, p. 593), take place in face-to-face relations (Smith, Smith, \& Shaw, 2017). In other words, in the offline environment, resources stemming from bonding social capital (originated from more intense and frequent face-to-face relations) and from bridging social capital (originated from more distant and unusual relations) can coexist (Burt, 2009, 2015; Coleman, 1988, 1990; Granovetter, 1973). The same may occur, theoretically, in the online environment. Some evidence suggest that entrepreneurs can - in the digital environment represented by the performance of entrepreneurs in the social media, e.g. Facebook, Twitter, WhatsApp among others - accumulate and benefit from both kinds of social capital (bonding and bridging) (Smith, Smith, \& Shaw, 2017).

In an essay published by the Journal of Business Venturing focusing on the social capital of entrepreneurs in the online environment, Smith, Smith and Shaw (2017) emphasize how entrepreneurs can - also in the digital context - create, accumulate and benefit from bonding and bridging social capital. According to the own authors, they "focus on network broadening and network deepening behaviors because they are known to help entrepreneurs accrue bridging and bonding social capital", respectively (Smith, Smith \& Shaw, 2017, p. 18). Smith, Smith, and Shaw (2017) suggest the analysis of capital social online through the performance of entrepreneurs in the social media, a.k.a. social network sites. Defined as spaces that allow users to create public profiles (Boyd \& Ellison, 2007), social media can be used with different purposes (Smith, Smith \& Shaw, 2017).

For entrepreneurs, however, social media seems to present specific functions and characteristics (Kaplan \& Haenlein, 2010; Smith, Smith \& Shaw, 2017). The search for online social capital is riskier for entrepreneurs when compared to other individuals; the importance

\begin{tabular}{|c|c|}
\hline Dimensions of social capital & Derived resources \\
\hline $\begin{array}{l}\text { Bonding social capital Coleman }(1988,1990) \text {, Granovetter }(1973 \text {, } \\
\text { 1983) }\end{array}$ & $\begin{array}{l}\text { (1) Obligations and trust } \\
\text { (2) Mutual aid } \\
\text { (3) Facilitated access to resources }\end{array}$ \\
\hline $\begin{array}{l}\text { Bridging social capital Burt (2009, 2015), Granovetter (1973, } \\
\text { 1983) }\end{array}$ & $\begin{array}{l}\text { (1) Access to new information/other } \\
\text { resources }\end{array}$ \\
\hline
\end{tabular}

Influence of social capital

397

Source(s): Authors (2020)

Table $\mathbf{1 .}$
Reflections on social capital offline, derived resources and references 
REGE 27,4

398 of capital for venture success depends on the effective management of social capital (Smith, Smith \& Shaw, 2017). According to the authors, social media relies on technological resources that not only influence the behavior of entrepreneurs in the online context but also allow them to behave differently in offline interactions (Smith, Smith \& Shaw, 2017). For example, social network sites "have the capacity to help entrepreneurs initiate weak ties and manage strong ones" (Smith, Smith \& Shaw, 2017, p. 19). Four of these resources are currently emphasized in the literature: (1) digital user profiles; (2) digital search; (3) digital relations and (4) network transparency (Kane, Alavi, Labianca \& Borgatti, 2014; Smith, Smith \& Shaw, 2017). They allow entrepreneurs, in the digital environment, to create and obtain both kinds of social capital (bonding and bridging) (Smith, Smith, \& Shaw, 2017).

Digital user profiles display data provided by users, letting entrepreneurs create, edit, share and/or duplicate information that provide insights into others (Smith, Smith \& Shaw, 2017). Indeed, "profiles often include [...] information about [...] identity, values, and character, among other attributes" (Smith, Smith \& Shaw, 2017, p. 22). Digital search is a resource of social media that allows entrepreneurs to scan, see, review or extract "network content" (Smith, Smith \& Shaw, 2017, p. 22). The third resource, digital relations, indicates that "entrepreneurs can easily and cost-effectively interact with others to develop weak and strong ties [...]" (Smith, Smith \& Shaw, 2017, p. 22). Finally, network transparency is a resource of social media that shows the user's network in its entirely. "This provides entrepreneurs and their contacts opportunities to view connections, identify missing connections, and make inferences about association or disassociation" (Smith, Smith \& Shaw, 2017, p. 22).

Each one of these four resources has technical capabilities, denominated by the authors as “affordances" (Smith, Smith \& Shaw, 2017, p. 18). These technical capabilities influence entrepreneurs' broadening and deepening behaviors used to create and benefit from bonding and bridging social capitals, respectively. In other words, they impact the way through which entrepreneurs broaden and deepen their digital networks, creating and/or benefiting from bonding and bridging social capitals (Smith, Smith \& Shaw, 2017, p. 18). Conforming to Smith, Smith and Shaw (2017), the creation, the accrual and the use of bonding and bridging social capital in the digital sphere are only possible through entrepreneurial behavior. Such behavior, which can be found in the online environment through the technical capabilities of social media sites, aims at deepening the immersion/interaction of the network relations or to reach out to new contacts and establish an interpersonal knowledge of them. When pursuing bonding social capital, entrepreneurs tend to reach for emotional support and provide or access limited or scarce resources among others. When pursuing bridging social capital, the behaviors used to broaden the network involve connecting (bridging) individuals and adding weak ties into the network (Smith, Smith \& Shaw, 2017).

There are 16 affordances: asynchronicity; association; shareability; reviewability; editability; scalability; social interactivity; interoperability; persistence; searchability; retrievability; replicability; signaling; transversability; viewability and visibility (Smith, Smith \& Shaw, 2017). Table 2 summarizes the definitions presented by Smith, Smith and Shaw (2017).

These 16 affordances are divided in two different groups. The first one encompasses the four technological resources of social media websites: (1) digital user profiles; (2) digital search; (3) digital relations and (4) network transparency. The second group is made up by the kinds of social capital (bonding and/or bridging) that each "behavioral capacity" allows through entrepreneurial behavior. In other words, according to Smith, Smith and Shaw (2017), some technical capabilities influence entrepreneurs' attitudes, which allow - in the online environment - to create and to benefit from bonding social capital (e.g. shareability and persistence). Other capabilities allow only the bridging social capital (e.g. replicability and association). There are still others that allow behaviors related to the creation of and benefit 
from bonding and bridging social capitals (e.g. scalability and interoperability). Table 3 summarizes this information displayed in a matrix.

Based on the information presented herein, it is possible to build a new conceptual model, which can be eventually able to provide better support about the influence of social capital on the development of entrepreneurs and early-stage ventures. Figure 1 illustrates the conceptual model and summarizes the propositions presented herein.

Considering the conceptual model we proposed, it is possible to draw some fundamental propositions: the first is that entrepreneurs can be influenced by resources stemming from the combination between social capital offline and online. In other words, in order to achieve the development of their ventures, entrepreneurs focus on the benefits gained from both capitals. The second proposition is that, when using social capital offline and online, entrepreneurs benefit from resources stemming from the association between bonding and bridging capital. In other words, entrepreneurs want to benefit from closest contacts and from the connection with distant actors in the offline and online environments. Such reflection leads to the deduction that the trajectory of entrepreneurs, i.e. ventures, tend to become more successful
Influence of social capital

399

\begin{tabular}{ll}
\hline Behavioral capability & Definition \\
\hline Asynchronicity & Ability to overcome temporal limitations and extract content from one-way ties \\
Association & Ability to know that a network connection exists \\
Shareability & Ability to easily share profile content with many others online \\
Reviewability & Ability to review for consistency in posts over time \\
Editability & Ability to reconsider/recraft profile content before sharing it \\
Scalability & Ability to send and receive information on a large scale \\
Social interactivity & Ability to efficiently connect to networked others \\
Interoperability & Ability to easily share content across multiple distinct platforms \\
Persistence & Ability to see archived information \\
Searchability & Ability to efficiently search all manner of social network site content \\
Retrievability & Ability to scan vast networks to capture specific information \\
Replicability & Ability to easily duplicate or modify profile content that looks original \\
Signaling & Ability to convey intended and unintended information from user profiles \\
Transversability & Ability to navigate to and through your own and others' networks \\
Viewability & Ability to view aspects of otherwise restricted profile content \\
Source(s): Adapted from & Smith
\end{tabular}

Source(s): Adapted from Smith, Smith, and Shaw (2017, p. 21)

Table 2. Technical capabilities of social network sites (online)

\begin{tabular}{lll}
\hline & Bonding & Bridging \\
\hline Digital user profiles & Shareability & Signaling \\
& Signaling & Replicability \\
& Viewability & - \\
Digital search & Editability & - \\
& Persistence & Searchability \\
& Reviewability & Retrievability \\
Digital relations & Asynchronicity & Asynchronicity \\
& Social interactivity & Social interactivity \\
& Scalability & Scalability \\
Network transparency & Interoperability & Interoperability \\
& Visibility & Visibility \\
& - & Association \\
& - & Transversability
\end{tabular}

Source(s): Adapted from Smith, Smith and Shaw (2017)

Table 3.

Resources of social network sites, its respective technical capabilities and the kind of social capital (bonding or bridging) allowed 


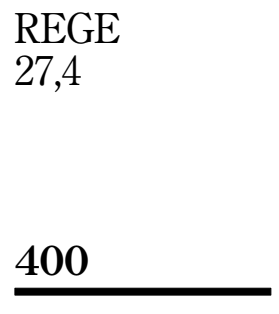

Figure 1.

Proposed conceptual model

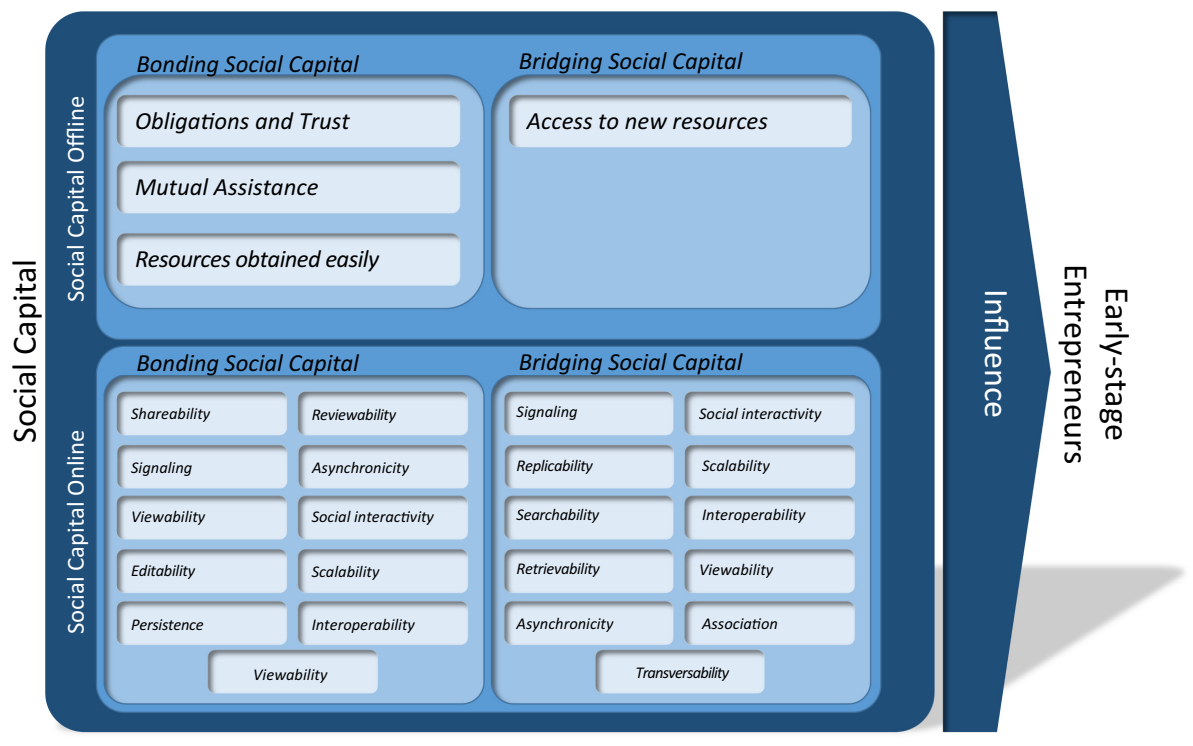

as far as entrepreneurs take advantage from bonding and bridging resources stemming from both social capitals (offline and online).

\section{Methodology}

We used herein a qualitative research approach, which is considered adequate when investigating social capital offline and online taking into account that operational measures have not been established yet (Smith, Smith \& Shaw, 2017). In fact, as emphasized by Smith, Smith and Shaw (2017, p. 31), "given the newness of the SNSs, the lack of establishment measures of key constructs and the challenge of separating online from offline networking behaviors", qualitative strategies are more appropriate. According to the authors, qualitative methodologies - in which case studies are inserted - "are particularly suitable for sifting through the complexity of entrepreneurs' social capital online" (Smith, Smith \& Shaw, 2017, p. 31). We used herein multiple case studies, whose evidence is considered more robust (Yin, 2015).

The ventures were the cases studied herein. The entrepreneurs responsible for such ventures are the unit of analysis and the unit of observation (Yin, 2015). We selected three cases for analysis: Peppers Free (Case \#1), Garden Services Ltd. (Case \#2) and Globe Events and Tourism (Case \#3). The entrepreneurs' and companies' names were changed for ethical reasons. The definition of the cases was based on the research questions; their selection (Gaskell, 2002) took into consideration some essential criteria.

The first criterion was the existence of the venture (up to 42 months), according to the classification adopted by GEM (2018). The second criterion was the size of the venture; we chose small-sized businesses because they have - theoretically - less resources and are more prone to failure and mortality during early stages (Fosić, Kristić, \& Trusić, 2017). Accordingly, Nassif, Corrêa, and Rossetto (2020) emphasize that micro and small-sized businesses are more susceptible to market oscillations. Furthermore, studying such ventures also indicates an empirical relevance, considering that $98.5 \%$ of approximately five million businesses in Brazil are made up by micro and small-sized companies (Nassif, Corrêa \& 
Rosseto, 2020). The third criterion was theoretical. Entrepreneurs would need to create an account in one or more social media (Facebook, Twitter, WhatsApp, LinkedIn or Instagram) and use such platforms as technological instruments to support their business. The fourth criterion was convenience and accessibility: all businesses are in the city of São Paulo, Brazil.

The first venture is a small company that manufactures homemade pepper sauce, canned food and marmalade, whose gross annual income is $\mathrm{R} \$ 180.000,00$. The second company provides architectural services for companies, in addition to the creation and maintenance of gardens; its average annual revenue is $\mathrm{R} \$ 100.000,00$. The third is a travel agency with a gross annual income of $\mathrm{R} \$ 40.000,00$.

We carried out in-depth semistructured interviews, which are one of the most important data collection techniques in the case study (Gaskell, 2002; Yin, 2015). The interviews were carried out with the entrepreneurs responsible for the creation and conduction of the ventures. The objectives of the interviews were as follows: (1) to perceive evidences of social capital offline and online; i.e. resources eventually achieved by the entrepreneurs in each social sphere and (2) how both capitals influence the entrepreneurs and their ventures. In other words, the purpose was to identify if the entrepreneurs had facilitated benefits - in the offline context - such as trust or mutual aid (bonding social capital) or if they had access to new unavailable information through close contacts (bridging social capital). In the online environment, the objective was to identify how entrepreneurs develop technical capabilities for the social media to eventually create or benefit from bonding and bridging social capital. Moreover, the purpose was to analyze which eventual benefits (bonding and bridging) entrepreneurs get from the "technical capabilities of social network sites".

The data collection was based on the logic of theoretical saturation, in which the interviews - carried out in more than just one face-to-face meeting - were ended when the evidence was confirmed (Yin, 2015). In other words, when the speeches did not indicate additional and significant contribution to the data analysis and conclusion of the research (Paiva Júnior, Leão \& Mello, 2011), the analysis relied on theoretical propositions, i.e. the theoretical orientation guided the case study analysis (Yin, 2015). The discussion was made based on the analysis of the cases, in which the information of individual cases was presented with the reflections, grouped according to a theory (Yin, 2015).

\section{Data analysis}

Empirical data show the influence of the social capital offline, which is to be understood as the combination between two fundamental dimensions (bonding and bridging) to early-stage entrepreneurs. Such statement was observed in the three cases investigated. Regarding bonding social capital, it is possible to understand how entrepreneurs' partially dense networks provided them with resources considered essential. Three of them, identified by Coleman $(1988,1990)$, were detected in our research: trust, mutual aid and facilitated access to resources. The first can be seen when, Marcos Paulo, the entrepreneurs responsible for Peppers Free (\#1) asked for his wife's support when starting his business. "Suddenly I said: let's start making sauces. I spoke with my wife, and she said she would help me, she is always there for me when we need to face new challenges". Trust can also be perceived when, Augusto Santos, the entrepreneur responsible for Globe Events (\#3), counted on the support of friends. "Back then, they were very important, they helped a lot".

Mutual aid, the second resource stemming from closest contacts (Coleman, 1988), was identified in cases \#2 and \#3. Augusto claimed that "I had the idea to plan an event with the theme 'black conscious'. My neighbors, João and Pedro, helped me organize it”. The mutual aid was an important resource used by Mariana Pereira, the entrepreneur responsible for Garden Services (\#2). She had her husband's support in developing different activities. "My husband helped a lot, not only physically, but also to develop the website of the company".

Influence of social capital 
REGE 27,4
Finally, the facilitated access to resources, the third attribute of dense networks emphasized by Coleman $(1988,1990)$ was achieved by entrepreneurs \#1, \#2 and \#3.

The inputs used in production by Marcos, which were essential for the first stage of the company, were initially donated by his mother. The entrepreneur affirmed that "she had lots of pepper and couldn't sell it all”. On the other hand, Mariana claims that her mother-in-law helped spread her work. According to her, "[my mother-in-law] works at a school. She invited my company to participate in a project as a collaborative company. [. . . A door opened and helped us to spread our work". Finally, Augusto had some help from the father of a friend (João), who gave thenecessary support to start the company. The entrepreneur emphasized that "back then I didn't know how to start a small company. João asked his father to create the firm legally because he worked at an accounting office. He didn't even charge me for the service".

Regarding bridging social capital (Burt, 2009, 2015), field research data suggest the importance of the connection with individuals immersed in different social structures; they evidence how distant contacts provided entrepreneurs with some essential resources. Bridging social capital allowed Marcos (\#1) to sell more products. He told us how a distant acquaintance he met in a fair helped him to start a business. "I talked to a commercial representative and showed him my products [...]. A week after that, he placed an order worth $R \$ 2,500.00$ ". Regarding Augusto (\#3) and Mariana (\#2), less frequent contacts allowed them to get in touch with individuals that would have been inaccessible otherwise. "First, a neighbor would indicate our services to others, a friend of a friend mentioned something about us, and suddenly all tickets were sold out”, emphasized Augusto (\#3). Mariana (\#2) also mentioned that a distant customer once "bought a box and invited us to plan an event in his condo".

There is, however, something beyond. Empirical data seem to focus on the manifestation of a complementary finding: social capital online, perceived both in the bonding and bridging social capital that entrepreneurs have access to through social media, seems to contribute to the development of early-stage ventures. Regarding bonding social capital, the resources become possible through two technical capabilities of digital media: persistence (ability to access archived information) and interoperability (ability to easily share content across distinct platforms).

Mariana (\#2), for instance, mentioned how "social media turned into a databank". According to her, "when we are with a customer, we check social media to see more information about the services performed [...]. This is the proof that we are professional and that we confirm our work". The possibility to "see archived information" associated with the "persistence" of social media (Smith, Smith \& Shaw, 2017) allows the entrepreneur to strengthen the relationship with customers, both in the on and offline context. "The benefit of social media, which we don't have in face-to-face interactions, is the possibility to establish a first contact [. . .]. But, in order to close the deal, we need a more direct, face-to-face, relationship", she complements.

On the other hand, interoperability, i.e. the ability to easily share content across multiple digital platforms (Smith, Smith \& Shaw, 2017), was mentioned by Marcos (\#1) and Augusto (\#3) as a technical capability used as source of resources. Interoperability contributes to spreading products and attracts different customers. "After organizing the products in the booth", pointed out by Marcos, "we took photos and posted them on Instagram, Facebook, and WhatsApp status. This way, everybody could see where we were and visit us".

It is possible to notice how the technical capabilities of digital media enable the existence of resources that also affect the face-to-face context (offline). The entrepreneurs make use of social media to strengthen the interaction with contacts in the online environment. In fact, according to Augusto (\#3), "stories on Facebook and WhatsApp status", a technical capacity associated with interoperability, "really works because I can see on the app messages of customers who want to participate". Moreover, there seems to be recursive between offline and online environments. According to Marcos (\#1), every time he met a customer in person, he requested his/her "WhatsApp contact to inform in which fair we would be the next week we didn't make use only of the messages, but also of the status". One can notice that the 
entrepreneur, on the one hand, benefited from face-to-face contacts to stimulate greater relational proximity in digital platforms (bonding social capital). On the other hand, the entrepreneur benefited precisely from the technical capabilities of digital media to create opportunities to interact with customers in the offline context.

Regarding the resources stemming from the intermediation between individuals distant from one another (bridging), entrepreneurs seem to be willing to make use of different technical capabilities on social media, corroborating and broadening the literature on this specific matter. We highlight eight of them: shareability, signaling, viewability, replicability, asynchronicity, searchability, retrievability and social interactivity. The first, i.e. the ability to easily share profile content with other individuals, was used by Mariana (\#2). According to her, "we take many photos from our work, which helps to constantly promote our work. [...] On Instagram, people started to contact us to work in other schools".

Signaling, which is the ability to convey intended and unintended information, was noticed by Marcos (\#1), for instance. He affirms that "when posting something from the company, I always make public posts so that other people can visualize and share it"; this way, the profile and the posts end up attracting new customers, which enhances the connection rate with individuals interested in the company's products. According to the entrepreneur, "when the social media profile is dynamic, it is recommended to other people with similar interest in what you are promoting. This is the way new customers are attracted". Such initiative ends up communicating "intended and unintended information about entrepreneurs and their ventures" (Smith, Smith \& Shaw, 2017, p. 24).

The viewability, i.e. the ability to view aspects of restricted profile content, seems to be an appropriate technical capability according to Marcos (\#1). He claims that "when creating a sponsored add on the company's profile, it is possible to choose the target group that will see this add. [...] I can choose the customer based on the distance from my company or based on the interest on homemade products". The replicability, which is the "ability to easily duplicate or modify profile content that looks original” (Smith, Smith \& Shaw, 2017, p. 22), could be observed by Mariana (\#2). According to her, "the good thing about promoting something on social media is that it allows interaction, modification and replication of the content over time". She complemented, "sometimes I see an old post, with a garden we created at a school, and I repost it, attracting new schools interested in this kind of job".

Asynchronicity, which is the ability to overcome temporal limitations extracting content from the ties, is a feature that was considered an appropriate technical capability by Marcos (\#1) and Mariana (\#2). "Every sale that starts on social media is later on completed on WhatsApp", according to Marcos. Mariana emphasized how the promotion on social media of lectures held in different schools ended up bringing new contracts to the company. In her own words, "we started to gain new customers from new schools due to this sort of job".

Another technical capability, the searchability (ability to search all manner of social media content), seems to be perceived by Augusto (\#3). He emphasizes how Facebook helped him during the early-stage development of his company. On Facebook, he could "search other companies that had the same core business I did, and I could see what these companies offered and how they worked". The retrievability, which is perceived as the possibility to scan networks to capture specific information, was used by Mariana (\#2) to analyze the behavior of the competition, which enabled her to provide a different service. According to her, the other company "did not replace any plants, I knew which products this company sold and how it promoted the products back then. I followed this company on Instagram". Finally, the social interactivity, i.e. the ability to efficiently connect to other individuals in the network, entails a few benefits according to Augusto (\#3). According to him, the ease to contact new individuals on digital platforms "helps a lot, because it is a way to promote our work".
Influence of social capital 
REGE 27,4
Some technical capabilities associated to bonding social capital in the digital context (shareability, signaling, viewability, editability, reviewability, asynchronicity, social interactivity, scalability and visibility) and bridging social capital (scalability, interoperability, association and transversability) were not considered relevant - despite their emphasis in literature (Smith, Smith \& Shaw, 2017) - for the early-stage entrepreneurs, we investigated. Shareability, for instance, is a technical capability related to bridging social capital that has not been yet identified by previous studies and that we identified herein.

Despite being considered a feature exclusively related to benefits stemming from bonding social capital, shareability was identified herein as a capability used to obtain resources stemming from the intermediation between individuals disconnected from one another (bridging). According to Mariana, "We take photos from everything we do, which enables us to constantly promote our job". Still according to her, "that is what happened with the school gardens. We started being asked by customers on Instagram to create a similar garden in different schools". One can perceive that the ease to share the entrepreneur's work on social media allows her to connect - in the digital environment - to other individuals, which would have been disconnected otherwise. Table 4 summarizes the field research's considerations, bringing together the propositions found in the literature.

\section{Final considerations}

The purpose of our article was to investigate if and how social capital offline and online could influence early-stage entrepreneurs, i.e. early-stage entrepreneurs, with businesses up to 42 months of existence. In order to achieve such goal, we elaborated in an innovative way a new conceptual model stemming from the association among constructs from both social spheres (offline and online). Field research evidence certifies the adequacy of the model developed herein and allows some fundamental observations. We highlight three of them herein. The first one is that social capital offline, considered in both bonding and bridging dimensions, influences the initial trajectory of the entrepreneurs investigated.

The same seems to occur with social capital online. The field research data suggest the confirmation that the trajectory of early-stage entrepreneurs is influenced by the combination between resources stemming from both offline and online contexts, i.e. by the ability that entrepreneurs develop in order to obtain attributes from face-to-face and digital relations. Therefore, the early stages of a venture should be, theoretically, more successful as far as entrepreneurs make use of bonding and bridging resources in both social spheres (offline and online).

A second observation is related to "how" social capital offline and online influence entrepreneurs. As pointed out herein, even though both are relevant when developing ventures, field research data suggest that the contributions of social capital offline are relatively distinct from the online context. While in the social capital offline, the resources stemming from dense networks are more relevant (bonding), in the online dimension the benefits inherent in the connection between distant and/or inaccessible individuals are more important (bridging). Such a finding does not suggest that bridging social capital in the offline context or that bonding social capital in the online context do not provide any contributions; the finding indicates only that they seem to be proportionally less evident regarding the analogous dimensions investigated herein.

A third consideration is related to the statement that social capital online influences the offline dimension and vice versa. Field research data suggest the presence of recursiveness in both spheres. Such a statement becomes evident through the statements made by Mariana (\#2) and Marcos (\#1). When she meets a customer in person, the entrepreneur searches "more information about the services performed [...]. This is the proof that we are professional and that we confirm our work". Marcos takes advantage of face-to-face contacts in order to 


\begin{tabular}{|c|c|c|c|c|c|c|c|c|c|c|c|c|c|}
\hline \multirow{7}{*}{ 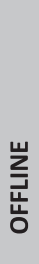 } & & \multicolumn{6}{|c|}{ OFFLINE } & \multicolumn{6}{|c|}{ ONLINE } \\
\hline & & \multicolumn{3}{|c|}{ Bonding } & \multicolumn{3}{|c|}{ Bridging } & \multicolumn{3}{|c|}{ Bonding } & \multicolumn{3}{|c|}{ Bridging } \\
\hline & & \multirow{2}{*}{$\begin{array}{c}\text { "L" } \\
\checkmark \\
\end{array}$} & \multicolumn{2}{|c|}{ "O" } & \multirow{2}{*}{$\begin{array}{c}\text { "L" } \\
-\end{array}$} & \multicolumn{2}{|c|}{ "O" } & \multirow{2}{*}{$\begin{array}{c}\text { "L" } \\
-\end{array}$} & \multicolumn{2}{|c|}{ "O" } & \multirow{2}{*}{$\begin{array}{c}\text { "L" } \\
-\end{array}$} & \multicolumn{2}{|c|}{ "O" } \\
\hline & Trust & & $\checkmark$ & 1,3 & & - & - & & - & - & & - & - \\
\hline & Mutual aid & $\checkmark$ & $\checkmark$ & 2,3 & - & - & - & - & - & - & - & - & - \\
\hline & Facilitated access to resources & $\checkmark$ & $\checkmark$ & $1,2,3$ & - & - & - & - & - & - & - & - & - \\
\hline & Access to new information/resources & - & - & - & $\checkmark$ & $\checkmark$ & $1,2,3$ & - & - & - & - & - & - \\
\hline \multirow{20}{*}{$\frac{\text { س }}{\underline{z}}$} & \multicolumn{13}{|l|}{ Digital User Profiles } \\
\hline & Shareability & - & - & - & - & - & - & $\checkmark$ & 冈 & - & 国 & $\checkmark$ & 2 \\
\hline & Signaling & - & - & - & - & - & - & $\checkmark$ & $\mathbf{x}$ & - & $\checkmark$ & $\checkmark$ & 1 \\
\hline & Viewability & - & - & - & - & - & - & $\checkmark$ & 凶 & - & 凶 & $\checkmark$ & 1 \\
\hline & Editability & - & - & - & - & - & - & $\checkmark$ & 凶 & - & - & - & - \\
\hline & Replicability & - & - & - & - & - & - & - & - & - & $\checkmark$ & $\checkmark$ & 2 \\
\hline & \multicolumn{13}{|l|}{ Digital Search } \\
\hline & Persistence & - & - & - & - & - & - & $\checkmark$ & $\checkmark$ & 2 & - & - & - \\
\hline & Reviewability & - & - & - & - & - & - & $\checkmark$ & 国 & - & - & - & - \\
\hline & Asynchronicity & - & - & - & - & - & - & $\checkmark$ & 国 & - & $\checkmark$ & $\checkmark$ & 1,2 \\
\hline & Searchability & - & - & - & - & - & - & - & - & - & $\checkmark$ & $\checkmark$ & 3 \\
\hline & Retrievability & - & - & - & - & - & - & - & - & - & $\checkmark$ & $\checkmark$ & 2 \\
\hline & \multicolumn{13}{|l|}{ Digital Relations } \\
\hline & Social Interactivity & - & - & - & - & - & - & $\checkmark$ & $\mathbf{x}$ & - & $\checkmark$ & $\checkmark$ & 3 \\
\hline & Scalability & - & - & - & - & - & - & $\checkmark$ & 国 & - & $\checkmark$ & 国 & - \\
\hline & Interoperability & - & - & - & - & - & - & $\checkmark$ & $\checkmark$ & 1,3 & $\checkmark$ & 冈 & - \\
\hline & \multicolumn{13}{|l|}{ Network Transparency } \\
\hline & Visibility & - & - & - & - & - & - & $\checkmark$ & 冈 & & $\checkmark$ & 冈 & - \\
\hline & Association & - & - & - & - & - & - & - & - & - & $\checkmark$ & 凶 & - \\
\hline & Transversability & - & - & - & - & - & - & - & - & - & $\checkmark$ & 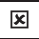 & - \\
\hline
\end{tabular}

Source(s): Authors (2020)

Legend: " $L "=$ literature; " $O$ " = Observed
Influence of social capital

405
Table 4 Interest categories and comparison to field evidence

stimulate further relations in the digital sphere; when he meets a new customer in the fairs, he requested his/her "WhatsApp contact to inform in which fair we would be the next week - we didn't make use only of the messages, but also of the status". In both cases it is possible to notice a relative influence of the off and online spheres. For Mariana, the online environment perceived in the ability of persistence - allowed her - through the data bank provided by the social media - to be more professional in the sales made in the offline context. For Marcos, the face-to-face contacts (offline) became an opportunity for him to establish future relationships on online platforms (online).

By pointing out these outcomes, our article brings important contributions. When emphasizing the influence of social capital offline and online, our study emphasizes the need for entrepreneurship researchers to consider the repercussion of social media in the creation and development of different kinds of venture. We highlight that many scholars of this 
REGE

27,4

406

specific research field are still less sensitive to the repercussion of social media in business ventures. The second outcome relates to the presentation of an original conceptual model, which arises from the association between capital social offline and online. By doing so, we strengthen and broaden the literature, which still focuses on the specific contributions of social capital online (Smith, Smith \& Shaw, 2017) and provide a set of variables that can be used in further research in the area. The third finding is related to the innovative way we approached not only the influence of both kinds of social capital (offline and online) regarding early-stage entrepreneurs but also the recursiveness between them. By analyzing some technical capabilities of social media, this article ends up endorsing the line of research that emphasizes how entrepreneurs create and benefit from social capital in the virtual environment. By emphasizing the social capital online, it was also possible to bring attention to relevant themes, including in the context of abrupt and emergency changes, e.g. the ones provoked by the impacts of COVID-19.

This article presents a few limitations: (1) the restrictive use of semistructured interviews as the only data collection instrument; (2) the data obtained are only related to the entrepreneurs and(3) theabsence of information on the performance of the ventures. Without such information, it was not possible to establish, for instance, causalities between social capital offline and online and entrepreneurial performance. New theoretical and empirical studies should not only overcome these limitations but also (1) test the contribution of shareability as a technical capability able to promote intermediation in social media, which was first identified herein; (2) investigate the influence of social capital offline and online on the creation and trajectory of different kinds of entrepreneurs, which would broaden a quite emergent line of research; (3) establish causal relations between social capital offline and online and entrepreneurial success and (4) compare the resources obtained from different entrepreneurs in the offline and online spheres, associating them with entrepreneurial performance among others.

\section{Note}

1. In English, Brazilian Service of Support for Micro and Small Ventures.

\section{References}

Afandi, E., Kermani, M., \& Mammadov, F. (2017). Social capital and entrepreneurial process. International Entrepreneurship and Management Journal, 13(3), 685-716.

Bastié, F., Cussy, P., \& Le Nadant, A.L. (2016). Network or independent business? Entrepreneurs' human, social and financial capital as determinants of mode of entry. Managerial and Decision Economics, 37(3), 167-181.

Bernardino, S., \& Freitas Santos, J. (2019). Network structure of the social entrepreneur: An analysis based on social organization features and entrepreneurs' demographic characteristics and organizational status. Journal of Social Entrepreneurship, 10(3), 346-366.

Birendra, K.C., Morais, D., Seekamp, E., Smith, J., \& Peterson, M. (2018). Bonding and bridging forms of social capital in wildlife tourism microentrepreneurship: An application of social network analysis. Sustainability, 10(2), 315-332.

Boyd, D.M., \& Ellison, N.B. (2007). Social network sites: Definition, history, and scholarship. Journal of Computer-mediated Communication, 13(1), 210-230.

Bucholtz, I. (2019). Bridging bonds: Latvian migrants' interpersonal ties on social networking sites. Media, Culture and Society, 41(1), 104-119.

Burt, R.S. (1997). The contingent value of social capital. Administrative Science Quarterly, 42(2), 339-365. 
Burt, R.S. (2009). The network entrepreneur. In R. Swedberg (Ed.), Entrepreneurship: The social science view. New York, NY: Oxford University Press, 281-307.

Burt, R.S. (2015). Reinforced structural holes. Social Networks, 43, 149-161.

Chen, Y., \& Zhou, X. (2017). Entrepreneurial self-efficacy and firms' innovation behavior: The negative mediating role of social capital. Social Behavior and Personality: An International Journal, 45(9), $1553-1562$.

Cho, Y.C., \& Sagynov, E. (2015). Exploring factors that affect usefulness, ease of use, trust, and purchase intention in the online environment. International Journal of Management and Information Systems (IJMIS), 19(1), 21-36.

Coleman, J.S. (1988). Social capital in the creation of human capital. The American Journal of Sociology, 94, 95-120.

Coleman, J.S. (1990). Social Capital. Cambridge: The Belknap Press of Harvard University Press, 300-321.

Fosić, I., Kristić, J., \& Trusić, A. (2017). Motivational factors: Drivers behind women entrepreneurs' decision to start an entrepreneurial venture in Croatia. Scientific Annals of Economics and Business, 64(3), 339-357.

Fukugawa, N. (2018). The contingent effect of social capital on performance of professional athletes: Life cycle stages and changes in regulation as moderators. Applied Economics, 50(15), 1676-1693.

Gaskell, G. (2002). Entrevistas individuais e grupais. In M. Bauer, \& G. Gaskell (Eds), Pesquisa Qualitativa com Texto, Imagem e Som: um Manual Prático. Petrópolis: Vozes, 64-83.

Giudici, G., Guerini, M., \& Rossi-Lamastra, C. (2018). Reward-based crowdfunding of entrepreneurial projects: The effect of local altruism and localized social capital on proponents' success. Small Business Economics, 50(2), 307-324.

Global Entrepreneurship Monitor (2018). Global Report 2017/18. London: Global Entrepreneurship Research Association (GERA).

Granovetter, M. (1973). The strength of weak ties. American Journal of Sociology, 78(6), 1360-1380.

Granovetter, M. (1983). The strength of weak ties: a network theory revisited. Sociological Theory, 1(1983), 201-233.

Han, J. (2018). Team-bonding and team-bridging social capital: Conceptualization and implications. Team Performance Management: An International Journal, 24(1/2), 17-42.

Hanna, R., Rohm, A., \& Crittenden, V.L. (2011). We're all connected: The power of the social media ecosystem. Business Horizons, 54(3), 265-273.

Hernández-Carrión, C., Camarero-Izquierdo, C., \& Gutiérrez-Cillán, J. (2017). Entrepreneurs' social capital and the economic performance of small businesses: The moderating role of competitive intensity and entrepreneurs' experience. Strategic Entrepreneurship Journal, 11(1), 61-89.

Kane, G.C., Alavi, M., Labianca, J., \& Borgatti, S. (2014). Integrating social networks and information systems: A review and framework for research. MIS Quarterly, 38(1), 275-304.

Kaplan, A.M., \& Haenlein, M. (2010). Users of the world, unite! the challenges and opportunities of Social Media. Business Horizons, 53(1), 59-68.

Kim, B.Y., \& Kang, Y. (2014). Social capital and entrepreneurial activity: A pseudo-panel approach. Journal of Economic Behavior and Organization, 97, 47-60.

Lang, R., \& Fink, M. (2019). Rural social entrepreneurship: The role of social capital within and across institutional levels. Journal of Rural Studies, 70, 155-168.

Lewis, P., \& Chamlee-Wright, E. (2008). Social embeddedness, social capital and the market process: an introduction to the special issue on austrian economics, economic sociology and social capital. Review of Austrian Economics, 21(2-3), 107-118. 
REGE 27,4

Luu, T. (2017). Ambidextrous leadership, entrepreneurial orientation, and operational performance: Organizational social capital as a moderator. Leadership and Organization Development Journal, 38(2), 229-253.

Mahmood, Q.K., Zakar, R., \& Zakar, M.Z. (2018). Role of Facebook use in predicting bridging and bonding social capital of Pakistani university students. Journal of Human Behavior in the Social Environment, 28(7), 856-873.

Naseri, S. (2017). Online social network sites and social capital: A case of Facebook. International Journal of Applied Sociology, 7(1), 13-19.

Nasir, N.A.B.M., Nawi, N.B.C., Mamun, A.A., Fazal, S.A., \& Raston, N.B.A. (2017). Examining the issues influencing the depth of social media usage as a business platform among student entrepreneurs. Advanced Science Letters, 23(9), 8210-8217.

Nassif, V.M.J., Corrêa, V.S., \& Rossetto, D.E. (2020). Estão Os empreendedores E as pequenas empresas preparadas para as adversidades contextuais? Uma reflexão À luz da pandemia do covid-19. Revista de Empreendedorismo e Gestão de Pequenas Empresas, 9(2).

Paiva Júnior, F.G., De Souza Leão, A.L.M., \& De Mello, S.C.B. (2011). Validade e confiabilidade na pesquisa qualitativa em administração. Revista de Ciências da Administração, 13(31), 190-209.

Pedrini, M., Bramanti, V., \& Cannatelli, B. (2016). The impact of national culture and social capital on corporate social responsibility attitude among immigrants entrepreneurs. Journal of Management and Governance, 20(4), 759-787.

Rooks, G., Klyver, K., \& Sserwanga, A. (2016). The context of social capital: A comparison of rural and urban entrepreneurs in Uganda. Entrepreneurship theory and Practice, 40(1), 111-130.

Ryu, S. (2017). To bond or to bridge? Contingent effects of managers' social capital on organizational performance. The American Review of Public Administration, 47(4), 403-418.

Smith, C., Smith, J.B., \& Shaw, E. (2017). Embracing digital networks: Entrepreneurs' social capital online. Journal of Business Venturing, 32(1), 18-34.

Stam, W., Arzlanian, S., \& Elfring, T. (2014). Social capital of entrepreneurs and small firm performance: A meta-analysis of contextual and methodological moderators. Journal of Business Venturing, 29(1), 152-173.

Vixathep, S. (2017). Entrepreneurship, human and social capital, and government policy in small and medium enterprise development in Laos. Japan Social Innovation Journal, 7(1), 33-50.

Wahid, F., \& Indarti, N. (2013). Facebook, online social capital, and the rise of nascent entrepreneurs. Recent Trends in Social and Behaviour Sciences - Proceedings of the 2nd International Congress on Interdisciplinary Behavior and Social Sciences 2013, ICIBSoS 2013, November 2013, 61-66.

Williams, D. (2006). On and off the' Net: scales for social capital in an online era. Journal of ComputerMediated Communication, 11(2), 593-628.

Williams, N., Huggins, R., \& Thompson, P. (2017). Social capital and entrepreneurship: Does the relationship hold in deprived urban neighbourhoods?. Growth and Change, 48(4), 719-743.

Yin, R.K. (2015). Estudo de Caso: Planejamento e Métodos. Porto alegre: Bookman.

Corresponding author

Victor Silva Corrêa can be contacted at: victorsilvacorrea@yahoo.com.br

Associate Editor: Luis Pinochet

For instructions on how to order reprints of this article, please visit our website:

www.emeraldgrouppublishing.com/licensing/reprints.htm

Or contact us for further details: permissions@emeraldinsight.com 